Journal of Engineering Sciences, Assiut University, Vol. 35, No. 4, pp. 945-956, July 2007

\title{
APPLICATIONS OF POLE SHIFTING SELF TUNING SPEED GOVERNOR CONTROLLERS FOR MULTIMACHINE POWER SYSTEMS
}

\author{
G. Shabib \\ Electrical Engineering Department, Aswan High Institute of Energy, \\ South Valley University, Aswan - Egypt \\ E-mail: gabershabib@yahoo.com
}

(Received February 21, 2007 Accepted June 10, 2007)

\begin{abstract}
Examination of the performance of fixed parameter controllers has resulted in the development of pole shifting strategies for speed governor control of multimachine power system. For a pole shifting controller design an input signal is incorporated in the self tuner. This input signal is of a composite output term of the terminal voltage and the rotor speed deviation of each generating unit. The control is based on a criterion which automatically generates a pole-shifting factor to shift the closed loop poles of the system towards the origin in the $z$ domain without violating the control constraints. The pole-shifting factor is depicted on line at each sampling instant depending on the error measurements of the terminal voltage of each generating unit. The output of the pole shifting controller is fed in the summing point of the speed governor of each unit of the multimachine power system. Digital simulations of a 9 bus, 3 machine of a multimachine power system are performed and the comparisons of conventional governor control and self tuning control performances are presented. Nonlinear digital simulation results show the effectiveness of the proposed technique to damp out the oscillation and work effectively over a wide range of loading conditions.
\end{abstract}

KEYWORDS: Control theory, Self tuning, Control equipment and applications

\section{INTRODUCTION}

The multimachine power system stabilization problem has attracted large interest in recent years $[1,2]$. The characteristics of a power system change significantly between heavy and light loading conditions, with varying numbers of generating units and transmission lines in operation at different times. Also, the magnitude of plant disturbances can vary from minor to large imbalances in mechanical and electrical generated power. The result is a highly complex and nonlinear system. Conventional controllers that using classical control theory, which employs linear transfer function models are only valid at a chosen set of operating conditions. So, The resulting conventional controllers is therefore unable to provide the most effective plant control over the full operating range [3-5].In order to have best controller gains over a wide range of loading conditions and to achieve better dynamic responses when the system 
is subjected to a severe disturbance causing a deviation in system operating condition, a self tuning controller with its parameters setting adapted in real time based on online measurements must be employed.

There have been significant developments in self tuning control in recent years [1-6], particularly in techniques based on pole placements and pole shifting methods [7-10]. Governor control also plays very important role in power system stabilization $[11,12]$. It has been shown that the combination of closing the main steam valves at maximum rate and forcing the field voltage to its maximum is very effective method to establish system stability after a fault. The successful use of fast valving methods to improve the power system stability and the availability of improved governor designs strengthen the possibility of using the governor control as a means of damping power system oscillations [11].

\section{SELF TUNING GOVERNOR CONTROLS}

Self tuning adaptive control algorithm is composed of a controller parameter identification which estimates the plant parameters from its input/output measurements and computation of the control output. The system output is sampled at discrete intervals of time to give a difference equation of the form

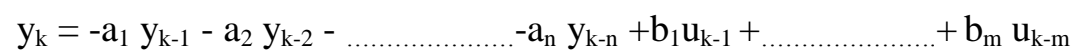

Eqn. (1) can be written as

$$
\mathrm{A}\left(\mathrm{z}^{-1}\right) \mathrm{y}_{\mathrm{k}}=\mathrm{B}\left(\mathrm{z}^{-1}\right) \mathrm{u}_{\mathrm{k}}+\mathrm{e}(\mathrm{t})
$$

where $\mathrm{A}$ and $\mathrm{B}$ are polynomials given by

$$
\begin{aligned}
& A_{j}\left(z^{-1}\right)=1+a_{1 j} z^{-1}+a_{2 j} z^{-2}+\ldots \ldots \ldots+a_{n j} z^{-n} \\
& B_{j}\left(z^{-1}\right)=1+b_{1 j} z^{-1}+b_{2 j} z^{-2}+\ldots \ldots \ldots+b_{n j} z^{-m}
\end{aligned}
$$

$\mathrm{u}$ is the input, $\mathrm{y}$ is the output, e is the model error, and $\mathrm{z}$ is the forward shift operator. If the parameters vector $\theta$ and the measurement vector $\phi$ are defined as

$$
\begin{aligned}
\theta & =\left[\mathrm{a}_{1} \mathrm{a}_{2} \ldots \ldots \ldots \ldots \ldots \ldots, \mathrm{a}_{\mathrm{n}}, \mathrm{b}_{1}, \mathrm{~b}_{2}, \ldots \ldots \ldots \ldots \ldots \ldots \ldots, \mathrm{b}_{\mathrm{m}}\right] \\
\phi & =[-\mathrm{y}(\mathrm{t}-1),-\mathrm{y}(\mathrm{t}-2), \ldots \ldots \ldots \ldots \ldots \ldots, \mathrm{y}(\mathrm{t}-\mathrm{n}), \mathrm{u}(\mathrm{t}-1), \mathrm{u}(\mathrm{t}-2), \ldots \ldots \ldots \ldots, \mathrm{u}(\mathrm{t}-\mathrm{m})]
\end{aligned}
$$

Then, Eqn. (2) can be written in compact form as;

$$
y(t)=\phi^{T}(t) \theta+e(t)
$$

The adaptive control design considered in this study is based on an identification of the transfer function between the system input $u$ and the output $y$ as shown in fig. (1). The recursive-least squares RLS identification technique [13] is used for the transfer function identification. The control is computed using a design technique named as the pole shifting technique. In Single input Single output pole shifting algorithm the control is computed such that the closed loop poles are placed closer to the center of the unit circle in the $\mathrm{z}$ plane than the open loop poles.

The control output can be obtained using the equation

$$
u_{k}=-\frac{G_{k}\left(z^{-1}\right)}{F_{k}\left(z^{-1}\right)} y_{k}
$$


where $F_{j}$ and $G_{j}$ are polynomials given by

$$
\begin{aligned}
& \mathrm{F}\left(\mathrm{z}^{-1}\right)=1+\mathrm{f}_{1} \mathrm{z}^{-1}+\ldots \ldots \ldots+\mathrm{f}_{(\mathrm{m}-1) \mathrm{j}} \mathrm{z}^{-\mathrm{m}+1} \\
& \mathrm{G}\left(\mathrm{z}^{-1}\right)=\mathrm{g}_{0}+\mathrm{g}_{1} \mathrm{z}^{-1}+\ldots \ldots+\mathrm{g}_{(\mathrm{n}-1) \mathrm{j}} \mathrm{z}^{-\mathrm{n}+1}
\end{aligned}
$$

The coefficients of the polynomials $F$ and $G$ are obtained from the solution of the identity

$$
A\left(z^{-1}\right) F\left(z^{-1}\right)+B\left(z^{-1}\right) G\left(z^{-1}\right)=T\left(z^{-1}\right)
$$

In pole assignment design, the system characteristic equation is given by

$$
\mathrm{T}\left(\mathrm{z}^{-1}\right)=1+\mathrm{t}_{\mathrm{j}} \mathrm{z}^{-1}+\ldots \ldots \ldots+\mathrm{t}_{\mathrm{r}} \mathrm{z}^{-\mathrm{r}}
$$

where $r$ is the order of the polynomial $T$, given by $r \leq n+m+1$

In pole shifting design, the polynomial $\mathrm{T}$ become

$$
\mathrm{T}\left(\mathrm{z}^{-1}\right)=\mathrm{A}\left(\boldsymbol{\alpha} \mathrm{z}^{-1}\right)
$$

$\alpha$ is a fraction $(1<\alpha<0)$ selected in such a way that the open loop positions are shifted radially towards the center. This technique offers the advantage of having a single parameter $\alpha$ instead of an entire set of parameters in a polynomials $T$.

The composite output variable of the generator $\mathrm{j}$ model is chosen as [14]:

$$
\mathrm{y}_{\mathrm{j}}(\mathrm{t})=\Delta \mathrm{V}_{\mathrm{tj}}(\mathrm{t})+\gamma_{\mathrm{j}} \Delta \omega_{\mathrm{j}}(\mathrm{t})
$$

where $\gamma_{\mathrm{j}}$ is a weighting factor for machine $\mathrm{j}\left(-1<\gamma_{\mathrm{j}}<0\right) . \Delta \omega_{\mathrm{j}}$ speed signal to enhance the damping of the system and $\Delta \mathrm{V}_{\mathrm{tj}}(\mathrm{t})=\mathrm{V}_{\mathrm{tj}}-\mathrm{V}_{\text {refj }}$.

The large change in output immediately following a fault is interpreted as a large identification error, requiring a large change in parameter estimates by the identifier. The solution to this problem is to turn off the identification for a short period following the onset of the fault. The onset of the fault is detected by a sudden rise of predication error after a period of good identification. For the studies described in this paper, the identification was recommended after a fixed interval of about $0.5 \mathrm{sec}$.

\section{STUDIED MULTIMACHINE POWER SYSTEM}

The sample multimachine power system to be studied in this paper is shown schematically in fig. (2). the system comprises three generating units, three transformers, 9 bus bars and 6 transmission lines. Base power for the system is $S_{b}=100$ MVA and base frequency is $f_{0}=60 \mathrm{~Hz}$. Unit 1 is hydraulic while unit 2 and 3 are nonreheat steam turbine. Each generating unit is represented by the two axis model for the synchronous machine with second order model for the shaft yielding fourth order model $[15,16]$.The data for each of the three generating units is given in Appendix 1 . Static type excitation is modeled for each generator unit [15].

To evaluate the performance of the self tuning controller the system response for the pole shifting technique is compared with the cases where there is no PSS and with conventional PSS in the system. The comparison is carried out under different kinds of study cases. These disturbances are the three phase fault with successful reclosure and three phase fault with line opening. 


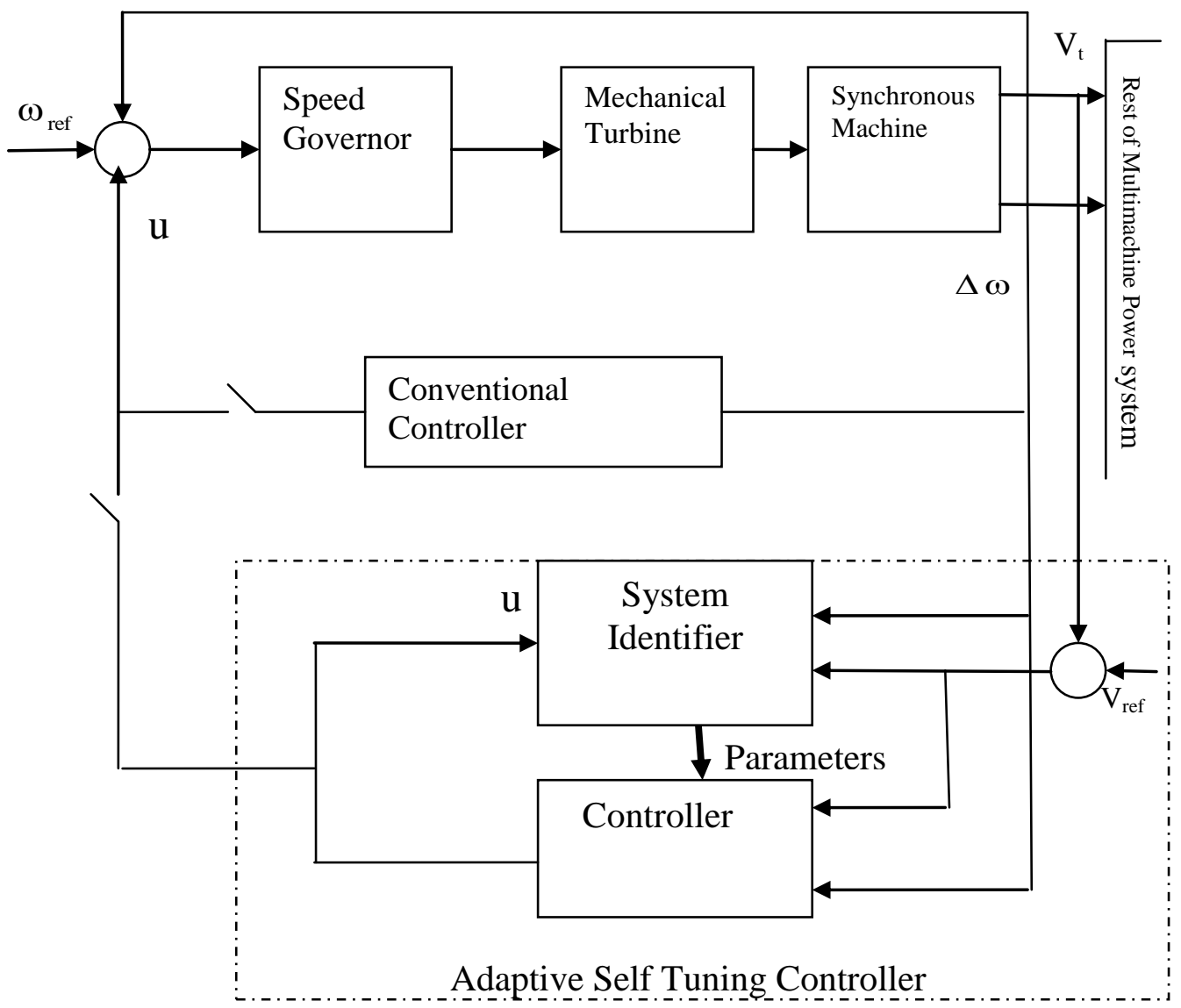

Fig.(1) Proposed speed governor control scheme

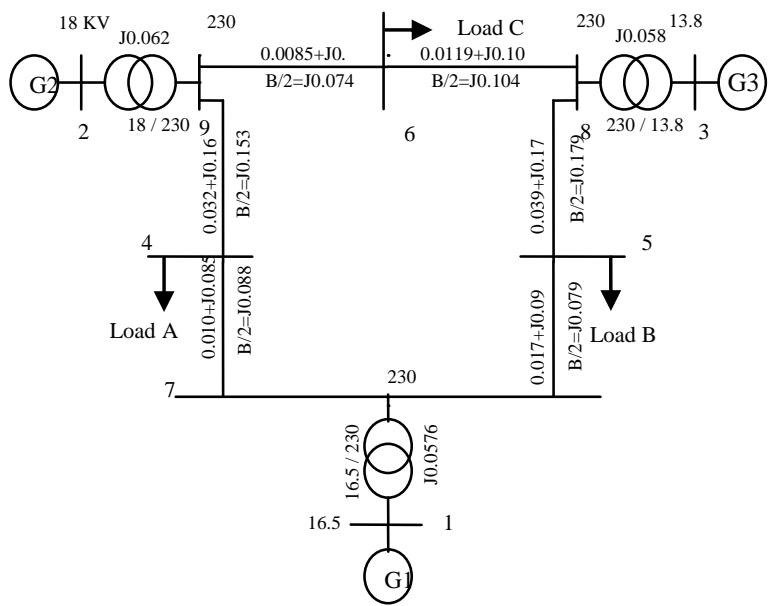

Fig.(2) Sample of multimachine power system 


\section{RESULTS}

\subsection{Three Phase Fault for 100ms with Successful Reclosure}

Here it is assumed that the multimachine power system operates under the nominal operating condition, and then a three phase short circuit at bus number 9 is applied and removed after a period of $100 \mathrm{~ms}$. The results of the simulation are shown in fig.3-6. The four plots show the variation of $\delta_{12}, \delta_{23}, \omega_{12}$ and $\omega_{23}$ with respect to the time. As we can been seen from the previous plots, the output (control signal) of the self tuning controller is able to track the fault and damp the oscillations resulted from the abnormal condition that the multimachine system exposed. The self tuning controller is extending the stability limits by modulating the generator speed governor to provide damping for the oscillations of the synchronous machine rotors relative to one another. The relative speed is approximately settled after the two swings. Fig. (7a-c) shows the dynamic of the gate power for the three units in this study case.

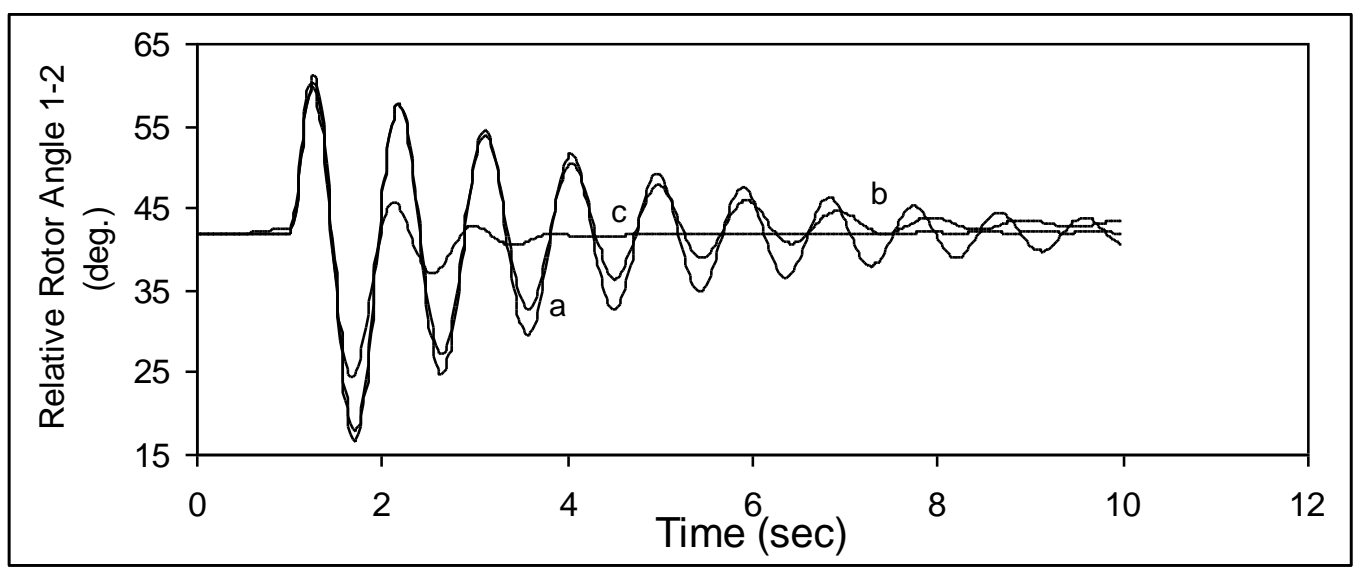

Figure 3 Relative rotor angle responses 1-2 to a three phase short circuit for $100 \mathrm{~ms}$ (a) without controller, (b) with conventional controller, (c) with Self tuning controller

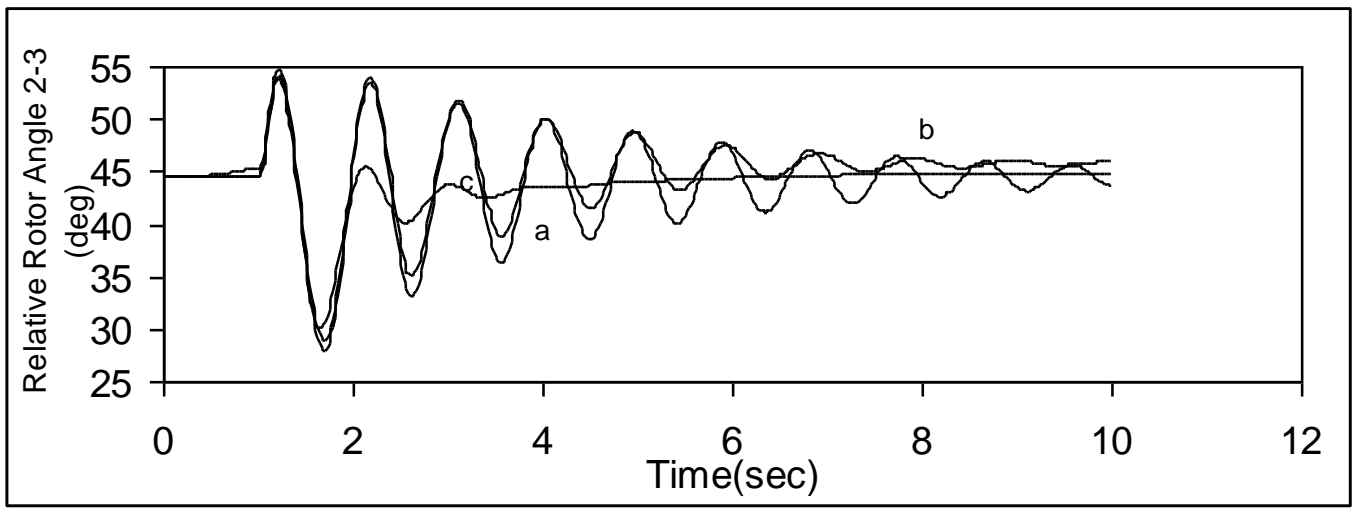

Figure 4 Relative rotor angle responses 2-3 to a three phase short circuit for $100 \mathrm{~ms}$ (a) without controller (b) with conventional controller (c) with Self tuning controller 


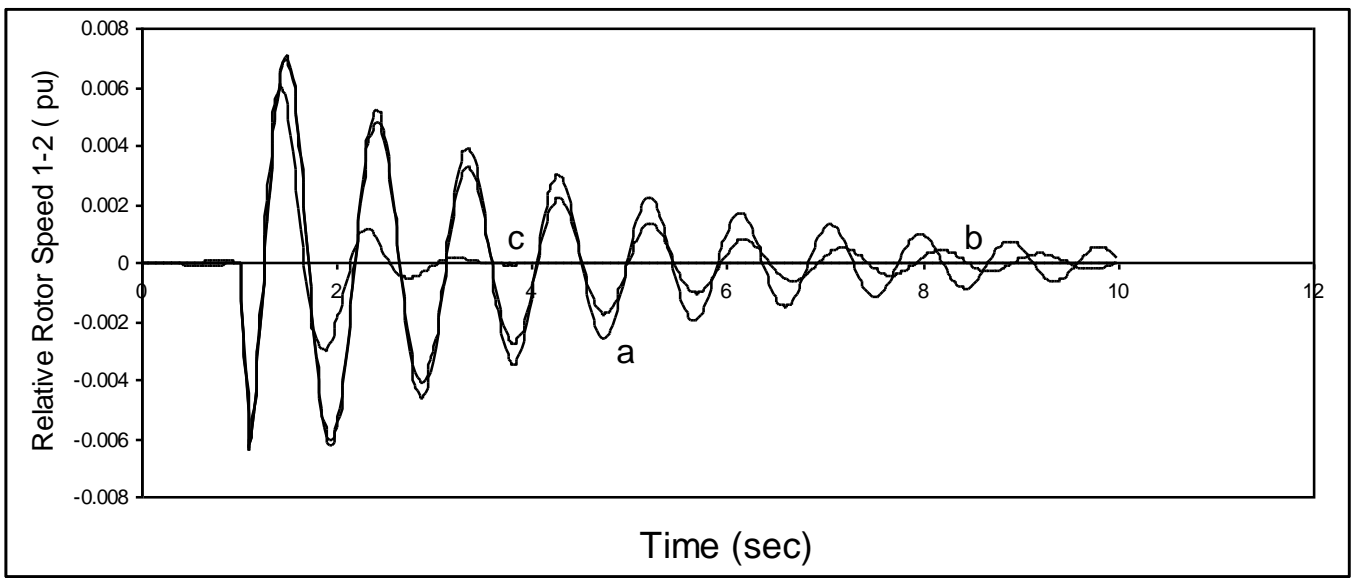

Figure 5 Relative rotor speed responses 1-2 to a three phase short circuit for $100 \mathrm{~ms}$. (a) without controller (b) with conventional controller (c) with Self tuning controller

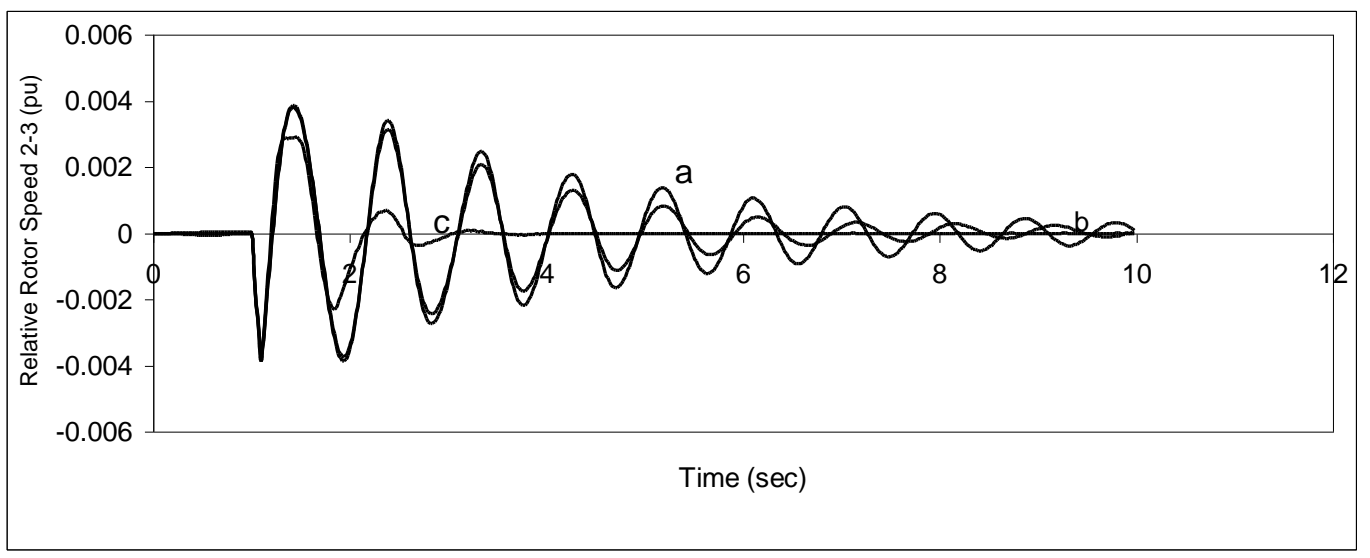

Figure 6 Relative rotor speed responses 2-3 to a three phase short circuit for $100 \mathrm{~ms}$. (a) without controller (b) with conventional controller (c) with Self tuning controller

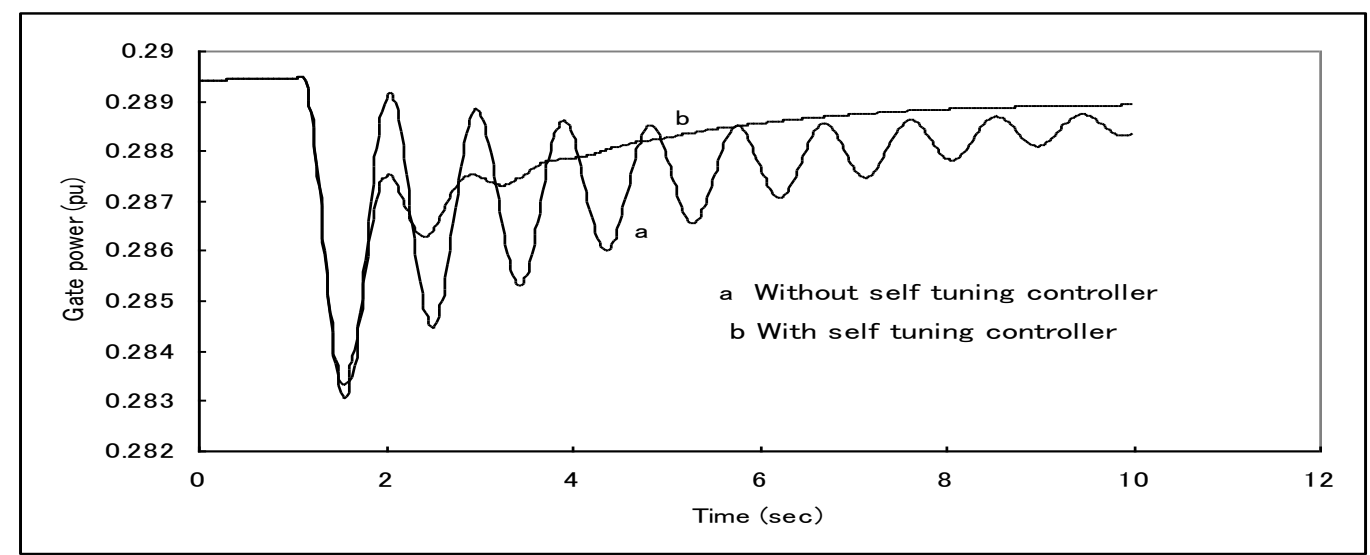

Figure 7(a) Gate power of unit 1 with a three phase short circuit for 100 ms study case 


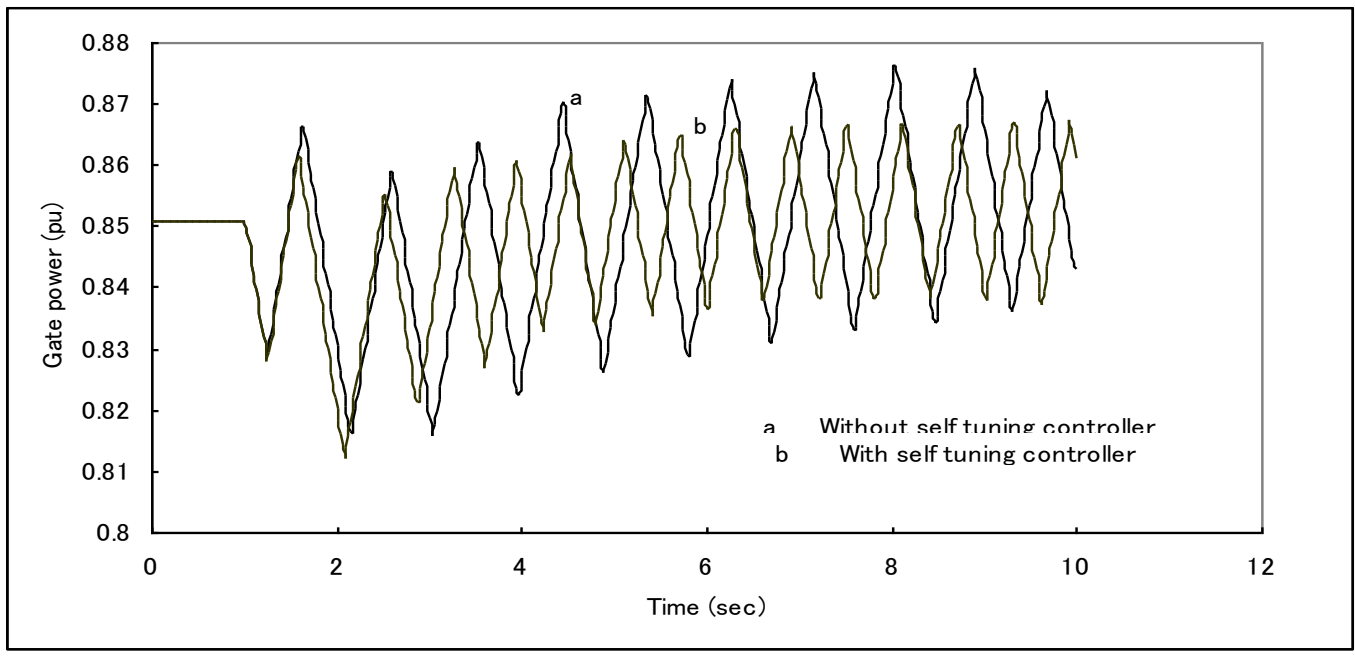

Figure 7(b) Gate power of unit 2 with a three phase short circuit for $100 \mathrm{~ms}$ study case

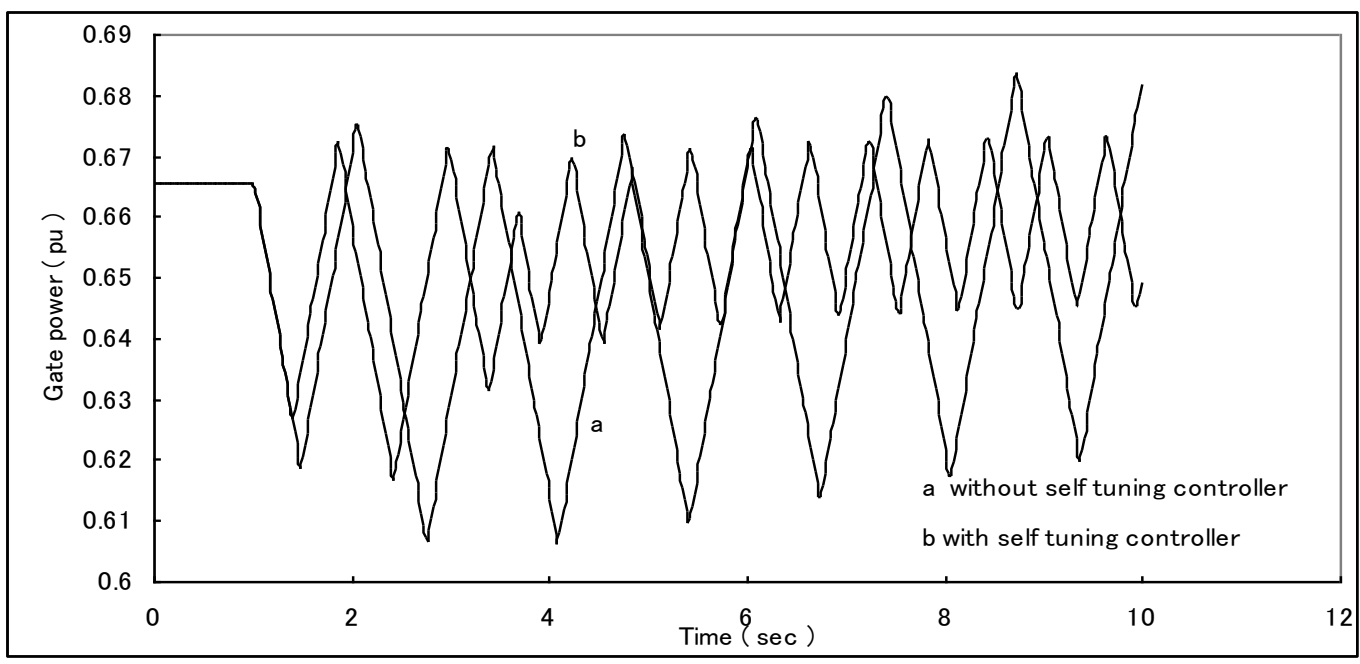

Figure 7(c) Gate power of unit 3 with a three phase short circuit for $100 \mathrm{~ms}$ study case

\subsection{Three Phase Fault with Line Opening}

Here it is assumed that the multimachine power system operates under the nominal operating condition, and then a three phase short circuit at bus number 9 is applied for a period of $100 \mathrm{~ms}$ followed by opening the line number 7-9. Fig. (8-11) indicate the results of numerical simulation results of numerical simulation of this study. Examination of 3-phase short circuit responses illustrates that the conventional controller scheme provides no satisfactory performance for applied conditions, while a well damped responses are achieved with the proposed pole shifting controller. However, it is observed that the actions of the proposed controller are clearly superior, with significant reduction in the overshoot of the first swing and improved damping of the subsequent oscillations, illustrating the transient behavior benefits of the PSS actions. 


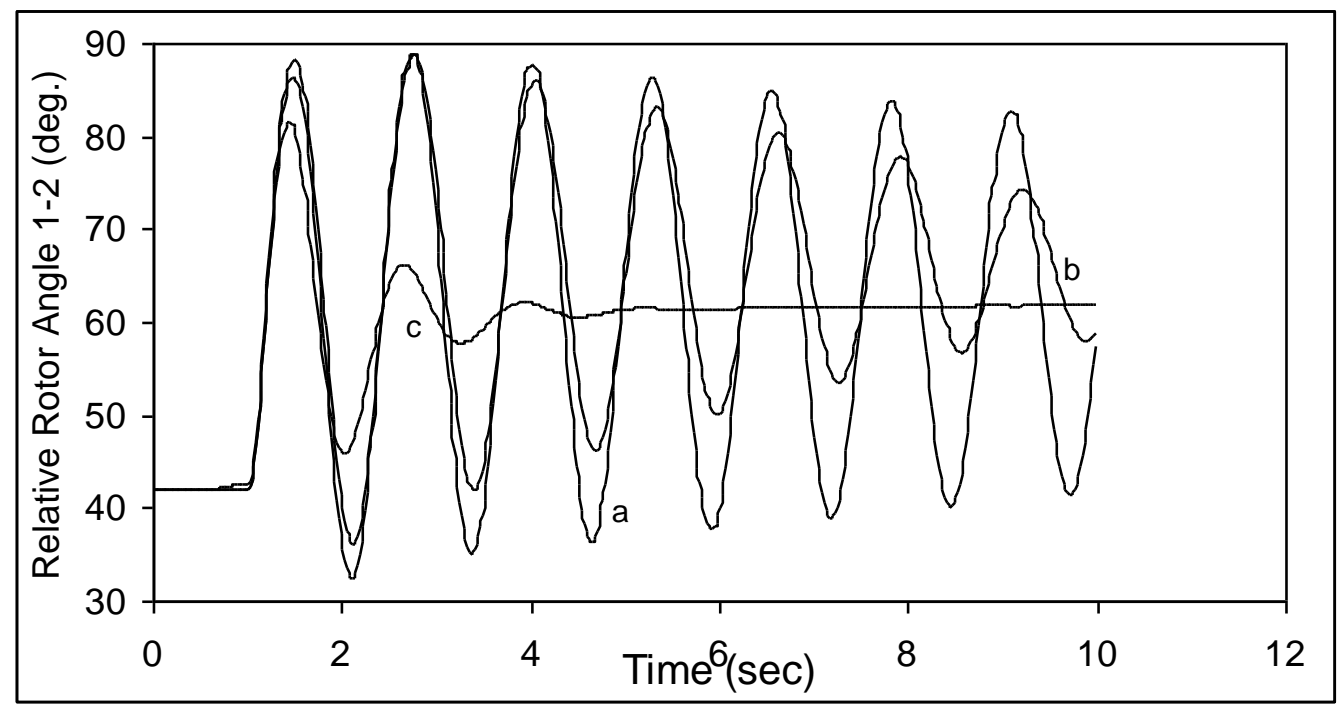

Figure 8 Relative rotor angle responses 1-2 to a three phase short circuit for $100 \mathrm{~ms}$ with line 7-9 opening. (a) without controller (b) with conventional controller (c) with self tuning controller

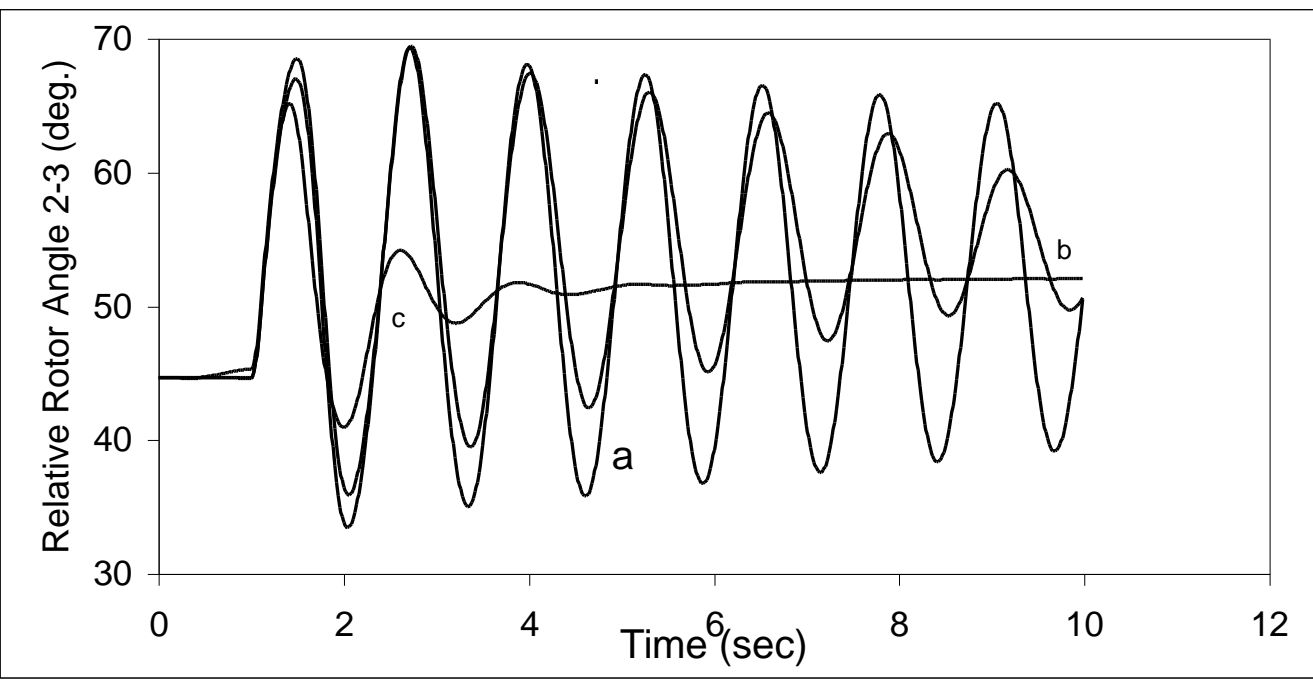

Figure 9 Relative rotor angle responses 2-3 to a three phase short circuit for $100 \mathrm{~ms}$ with line 7-9 opening. (a) without controller (b) with conventional controller (c) with self tuning controller 


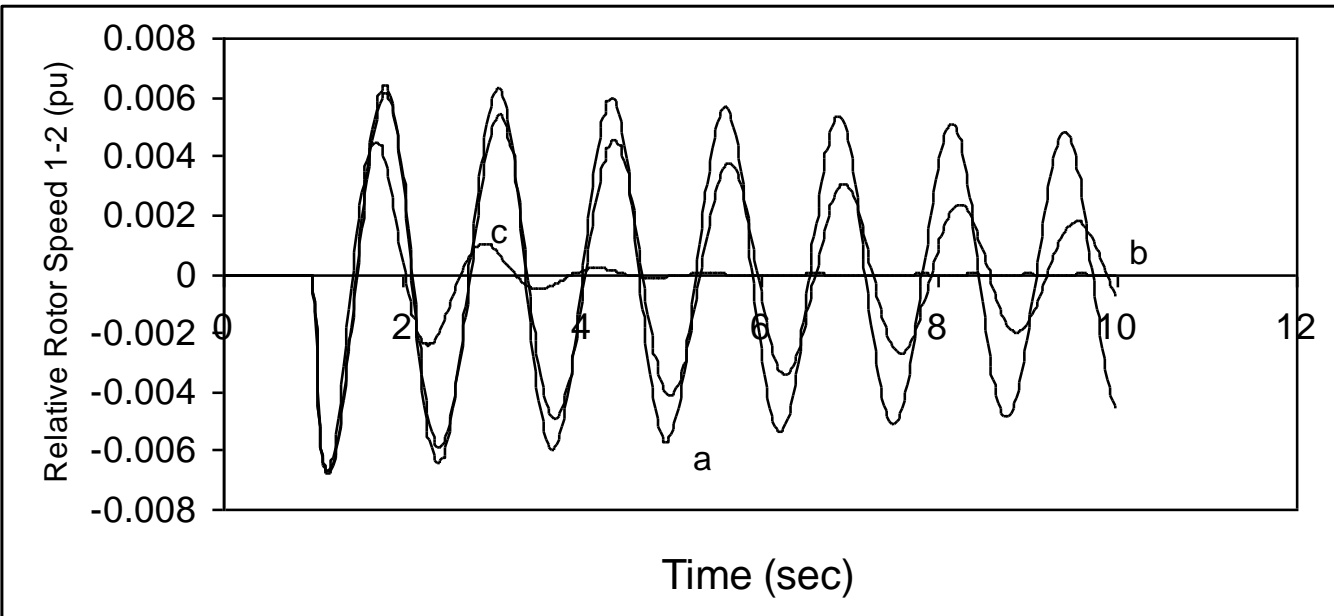

Figure 10 Relative rotor speed responses 1-2 to a three phase short circuit for $100 \mathrm{~ms}$ with line 7-9 opening. (a) without controller (b) with conventional controller (c) with self tuning controller

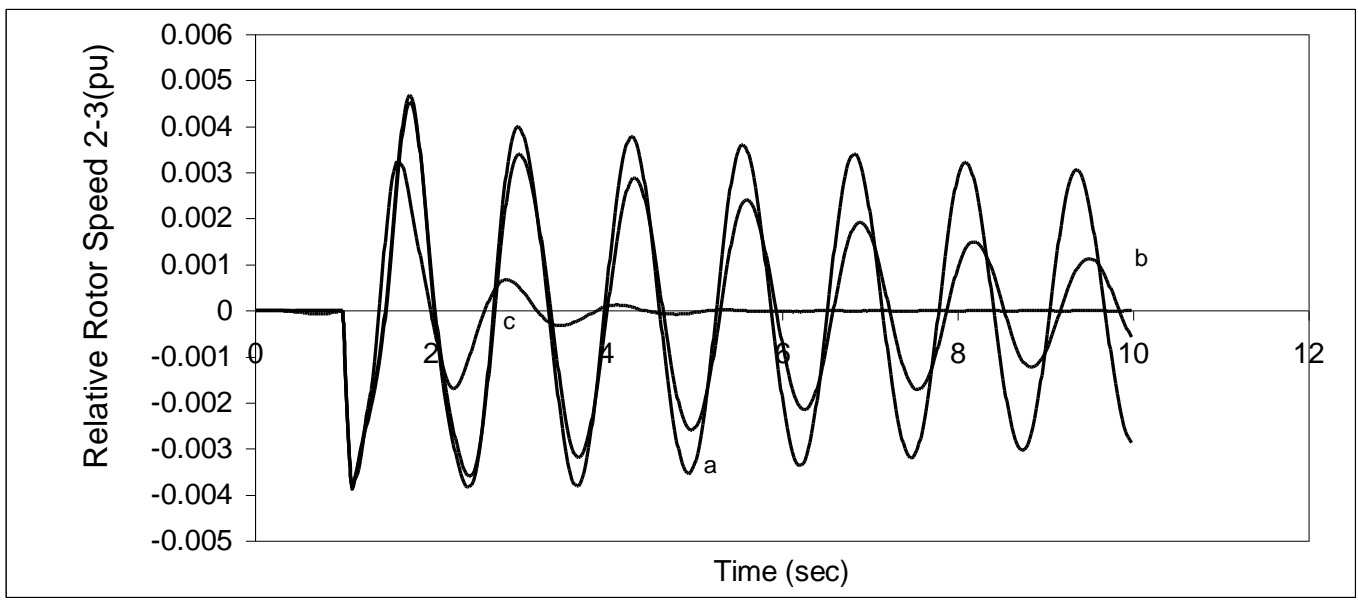

Figure 11 Relative rotor speed responses 2-3 to a three phase short circuit for $100 \mathrm{~ms}$ with line 7-9 opening. (a) without controller (b) with conventional controller (c) with self tuning controller

\section{CONCLUSIONS}

To overcome the drawbacks of the conventional power system stabilizers, a systematic approach of an adaptive self tuning control based power system stabilizer design is presented in this paper. The pole shifting controller is implemented on the speed governor loop of multimachine power systems. Results reported in this paper show that self tuning control is particularly appropriate, because they are highly non-linear, their dynamics change significantly with differences in load and also with time, and they are 
of random magnitude and duration. It has been shown that self tuning provides both effective control and reliable long term operation simulation. Practical assessment under dynamic and transient operating conditions have shown that self tuning control is far superior to conventional control methods.

Test results for two study cases show many comments. The following observations can be made from these results:

1- A machine when equipped with the proposed adaptive controller shows stronger damping than that equipped with conventional PSS.

2- When all machines in a system are equipped with adaptive controller, the whole system possesses strong damping characteristics. Better and fast damping means that generators can operate more close to their maximum generation capacity. Thus, ensuring that generator s remain stable under severe faults such as three phase short circuits. This means that more power generated per invested pound.

3- It is observed that a significant reduction in the overshoot of the first swing and improved damping of the subsequent oscillations obtained with using the proposed pole shifting controller in the case of three phase short circuit with line opening.

4- Conventional controllers cannot cope well with the operating points of the power system. Generator performance degrades, which drive the power system into undesirable operating states.

5- Tuning and integration of large number of control loops founded in power system may be costly and time consuming.

\section{REFERENCES}

1- A.H.M.A. Rahaim, E.P. Nowicki. And O.P. Malik, "Enhancement of power system dynamic performance through an on line self tuning adaptive controller", Electric power system research, Volume 76, Issues 9-10, June 2006 page 801-807.

2- A. Chandra, O. P. Malik, and G. S. Hope, "A Self tuning controller for the control of a multimachine power system ", IEEE Trans. PAS, Vol. 3, No. 3, 1988.

3- C. M. Lim and T. Hiyama, "Self tuning control scheme for stability enhancement of multimachine power systems ", Proc. IEE, Pt. C, Vol. 137, No. 4, 1990.

4-Q. H. Wu, B. W. Hogg, "Self tuning control for turbo generators in multimachine power systems ", IEE Proc., Vol. 137, Pt. C, No. 2, March 1990.

5- E. Swidenbank, M.D.Brown and D.Flynn, "Self tuning turbine generator control for power plant", Mechatronics, Volume 9, Issues 5, August 1999, page 513-537.

6- G. Shabib, "Multimachine Power System Stabilizers Applying a New Adaptive Pole Shifting Algorithm", Journal of Engineering Science - Faculty of Engineering - University of Assuit - Egypt ,September 2005

7- G. Ramakrishna, O. P. Malik, "RBF Identifier and Pole Shifting Controller for PSS Application", International Electric Machine and Drives Conference IEEE IEMDC'99, May 9-12 1999, Washington, USA

8- A. Ghandakly, J. J. Dai, "An Adaptive Synchronous Generator Stabilizer Design by Generalized Multivariable Pole Shifting (GMPS) Technique", IEEE Transactions on Power Systems, August 1992 
9- M. L Kothari, K. Bhattacharya, J. Nanda, "Adaptive power system stabilizer based on pole shifting technique", IEE Proc. - Gener. - Transm. - Distrib., Vol. 143, No.1, Jan. 1996.

10- O. P. Malik, G. P. Chen, G. S. Hope, Y. H. Qin and G. Y. Xu, “Adaptive self optimizing pole shifting control algorithm ", Proc. IEE, Pt. D, Vol. 139, No. 5, 1982.

11- Malik, O. P. , Zeng, Y., "Design of a Robust Adaptive Controller for a Water turbine governing system ", IEEE Transactions on Energy Conversion, Vol. 10 June 1995

12- A. Ghandakly, Domingo Uy, "Design of a Digital PID Controller for AC Generator Excitation and Governor Control System", The Ohio Journal of Science, Vol. 83\# 2, April 1983

13- P. E. Wellstead ,M. B. Zarrop, “Self-tuning systems control and signal processing ", Book John wiley 1991.

14- A. S. Ibrahim, "Multivariable self-tuning controllers for industrial processes control", Ph. D Thesis University of Menoufia, 1987.

15- P. M. Anderson and A. A. Fouad, "Power system control and stability", Iowa State University Press, Ames, Iowa, 1998.

16- M.Z.El-Sadek, “ Power system Control ”, Muchtar Press, Assuit, Egypt, 2005.

\section{Appendix 1}

Parameters of the generators, all data in pu and time constant sec:

Synchronous machine data

G

Rated MVA

Rated KV

Rated P.F

Type

Speed

$\mathrm{X}_{\mathrm{d}}$

$X_{d}^{\prime}$

$\mathrm{X}_{\mathrm{q}}$

$\mathrm{X}_{\mathrm{q}}$

$\mathrm{X}_{1}$

$r_{a}$

$\mathrm{T}_{\mathrm{d} 0}^{\prime}$

$\mathrm{T}_{\mathrm{q} 0}$

D

H
1

247.5

16.5

1

Hydro

$180 \mathrm{r} / \mathrm{min}$

0.146

0.0608

0.0969

0.0969

0.0336

0.0016

8.96

1.5

0.3073

23.64
2

192

18

0.85

Steam

$3600 \mathrm{r} / \mathrm{min}$

0.8958

0.1198

0.8645

0.1969

0.0521

0.0026

6.0

0.535

0.8489

6.4
3

128

13.8

0.85

Steam

$3600 \mathrm{r} / \mathrm{min}$

1.3125

0.1815

1.2578

0.25

0.0472

0.0035

5.89

0.6

0.85

3.0 
Power System Stabilizer Data

$\begin{array}{lccclccc}\mathrm{G} \# & 1 & 2 & 3 & \mathrm{~T}_{\mathrm{R}} & 5.0 & \mathrm{~T}_{\mathrm{S}} & 0.15 \\ \mathrm{~K} & 10 & 20 & 20 & \mathrm{~T}_{\mathrm{S}} & 0.04 & \mathrm{~T}_{\mathrm{HP}} & 0.4 \\ \mathrm{~T}_{1} & 10 & 0.03 & 0.03 & \delta & 0.3 & \mathrm{~T}_{\mathrm{IP}} & 5.8 \\ \mathrm{~T}_{2} & 0.57 & 1.5 & 1.5 & \sigma & 0.05 & \mathrm{~T}_{\mathrm{LP}} & 0.5 \\ \mathrm{~T}_{3} & 0.10 & 0.14 & 0.14 & \mathrm{~T}_{\mathrm{W}} & 1.0 & \mathrm{~F}_{\mathrm{HP}} & 0.3 \\ \mathrm{U}_{\text {MAX }} & 0.12 & 0.12 & 0.12 & \mathrm{~g}_{\text {MAX }}^{\prime} & 0.1 & \mathrm{~F}_{\mathrm{IP}} & 0.4 \\ \mathrm{U}_{\text {MIN }} & -0.12 & -0.12 & -0.12 & \mathrm{~g}_{\text {MIN }}^{\prime} & -0.1 & \mathrm{~F}_{\mathrm{LP}} & 0.3 \\ & & & & \mathrm{R} & 5.0 & & \end{array}$

Static Exciter Data

$\begin{array}{lc}\mathrm{K}_{\mathrm{a}} & 200 \\ \mathrm{~T}_{\mathrm{a}} & 0.05 \\ \mathrm{~K}_{\mathrm{f}} & 0.03 \\ \mathrm{~T}_{\mathrm{f}} & 1.0 \\ \mathrm{~V}_{\text {rmin }} & -3.5 \\ \mathrm{~V}_{\text {rmax }} & 3.5\end{array}$

Loads Data

$\begin{array}{llccc} & & \text { Load A } & \text { Load B } & \text { Load C } \\ \mathrm{P}_{\mathrm{o}} & \text { MW } & 125.0 & 90.0 & 100.0 \\ \mathrm{Q}_{0} & \text { MVAR } & 50.0 & 30.0 & 35.0\end{array}$

\section{تطبيقات ازاحة الاقطاب على المحكمات ذاتية/التوليف لائرة مسيطر السرعة فى نظم القوى المتعددة الالات}

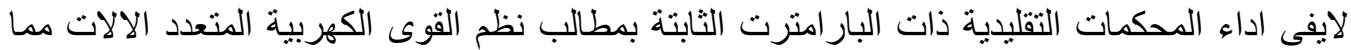

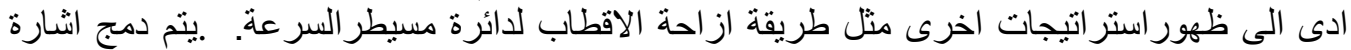

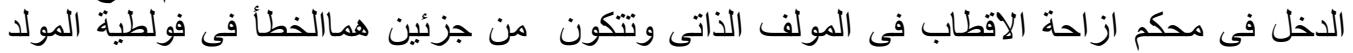

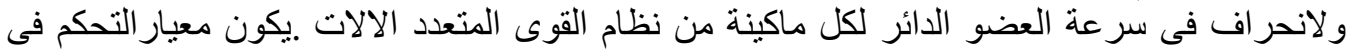

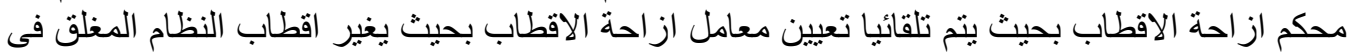

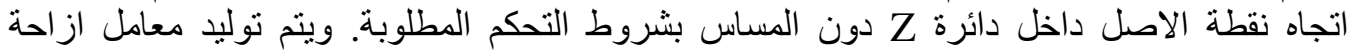

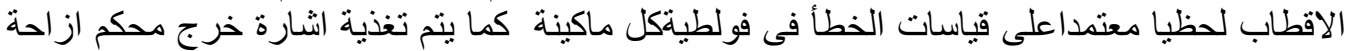

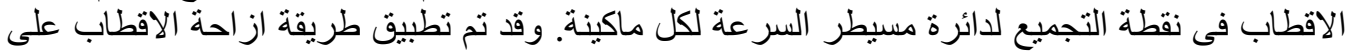

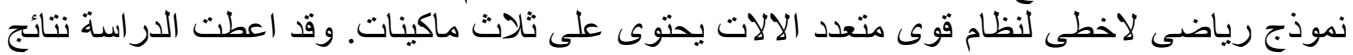

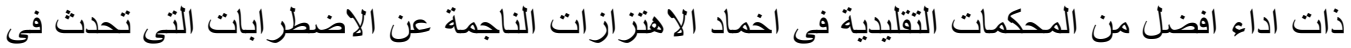

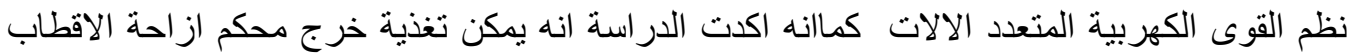
فى دائرة مسيطر السر عة بدلا من دائرةالمغذى الالى. 